\title{
Amplitude EEG Changes in Preterm Infants at NICU of Al-Zahraa University Hospital
}

\author{
Yomna Reda*, Zeinab Farag Oshaiba, Eatemad Nabil Mansour, Haidy Mahmoud Nasr \\ Al-Zahraa University, Abbassya, Egypt \\ Email: *yomna093@gmail.com
}

How to cite this paper: Reda, Y., Oshaiba, Z.F., Mansour, E.N. and Nasr, H.M. (2021) Amplitude EEG Changes in Preterm Infants at NICU of Al-Zaharaa University Hospital. Open Journal of Pediatrics, 11, 450-459.

https://doi.org/10.4236/ojped.2021.113042

Received: August 9, 2021

Accepted: September 10, 2021

Published: September 13, 2021

Copyright $\odot 2021$ by author(s) and Scientific Research Publishing Inc. This work is licensed under the Creative Commons Attribution International License (CC BY 4.0).

http://creativecommons.org/licenses/by/4.0/

\begin{abstract}
Background: With increase in the incidence of preterm birth, quality of life in premature infants who suffer from perinatal brain injury has become a major concern. Amplitude electroencephalogram has the advantages of being simple bedside monitoring for assessment of brain function and follow up in preterm neonates. Aim of Study: To evaluate the aEEG changes in preterm infants and compare it to cranial ultrasound. Patients and Methods: This was a prospective observational study conducted at the NICU of Al Zahraa University Hospital for a period from May 2020 to May 2021. Our study was conducted on 60 preterm infants $(26-36 \mathrm{w})$ in the first 7 days of life with exclusion of obvious congenital anomalies and hypoxic ischemic encephalopathy patients. Cranial ultrasound was performed on all the studied groups then aEEG recording was done for 4 hours. Results: The pattern of aEEG was discontinuous in patients with low gestational age and in infants small for gestational age. The pattern was also discontinuous in infants who had convulsions. Among our studied infants who had PROM, pre-eclampsia and experienced prolonged delivery, some infants had low voltage amplitude recording as well as infants with intraventricular hemorrhage grade III. Conclusion: This study confirms that aEEG background activity is strongly related to gestational age, birth weight, convulsions and IVH. Complications during delivery alter neonatal brain activity and aEEG background. Early aEEG combined with cranial ultrasound increases the sensitivity for detecting abnormal neurological outcome.
\end{abstract}

\section{Keywords}

Preterm, Convulsions, Amplitude EEG

\section{Introduction}

Preterm birth, defined as infants born before 37 completed weeks of gestation, is 
a disease of worldwide epidemic. Recent estimates show that approximately $10.6 \%$ of all live births globally are preterm, which brings about a global incidence of preterm birth of nearly 15 million per year [1]. Neuro-imaging and radiological examinations are of great significance in the diagnosis and evaluation of brain damage in preterm infants. At present, aEEG has been widely used to monitor the brain function of preterm infants with term asphyxia, and aEEG abnormality can be used as an early predictor of hypoxic-ischemic encephalopathy in term infants [2]. However, the application of aEEG in preterm infants is not universal. Recent studies have shown that abnormalities of aEEG are related to brain damage and poor neurological prognosis in preterm infant [3].

\section{Aim of the Study}

The aim of the study is to evaluate the aEEG changes in preterm infants and compare it to cranial ultrasound in NICU of Al-Zahraa University Hospital.

\section{Patients and Methods}

This was a prospective observational study which was conducted at the NICU of Al-Zahraa University Hospital for a period from May 2020 to May 2021. Our study was conducted on 60 preterm infants in the first 7 days of life. Obvious congenital anomalies and hypoxic ischemic encephalopathy patients are excluded. The studied neonates were 36 males and 24 females with gestational age ranged from (26 to 36 weeks).

All the included neonates were subjected to the following:

1) Full history taking:

a) Age during study enrollment.

b) Assessment of gestational age using Ballard score.

c) Detailed antenatal, natal and postnatal history.

d) Thorough clinical examination:

- Systemic examination of the baby (neurological, cardiac, chest and abdominal).

- Anthropometric measurements according to WHO growth charts: Birth weight, length and head circumference.

2) Investigations:

- Laboratory investigations: (CBC, CRP, ABG, electrolytes, bleeding profile, kidney and liver function tests).

- Cranial ultrasound during $1^{\text {st }}$ week of life.

- Amplitude EEG (aEEG) was recorded on the first week of life.

The aEEG was recorded for 4 hours as a four-channel EEG from ground, frontal zone $(\mathrm{Fz})$ and bi-parietal zones $\left(\mathrm{P}_{3} \& \mathrm{P}_{4}\right)$ using the electrodes from EEG device with neuro-spectrum software module for aEEG. In brief, the obtained signal was filtered, rectified, smoothed, and amplitude-integrated before it was printed out or digitally available on the monitor directly at the bedside.

The recordings were analyzed by two independent readers and registered as 
shown below:

1) Background activity:

- Continuous voltage pattern (CVP): continuous activity with minimum amplitude above $5 \mathrm{~V}$ and maximum amplitude above $25 \mathrm{~V}$.

- Discontinuous voltage pattern (DC): discontinuous activity with minimum amplitude below $5 \mathrm{~V}$ and maximum amplitude above $25 \mathrm{~V}$.

- Burst suppression: discontinuous activity with minimum amplitude without variability at $0-1 / 2 \mathrm{~V}$, and bursts with amplitude $>50 \mathrm{~V}$.

- Inactive, flat trace (FT): mainly inactive background (electro-cerebral inactivity) with amplitude always below $5 \mathrm{~V}$.

2) Seizures: characterized as an abrupt rise in minimum and maximum amplitude, categorized as single seizures (no more than one seizure per each period of $30 \mathrm{~min}$ of analysis), repetitive seizures (more than one electrographic seizure per each 30 min period of analysis but no more than one electrographic seizure over a $10 \mathrm{~min}$ period), or status epilepticus (ongoing seizure activity $>30 \mathrm{~min}$, present as "sawtooth pattern" or as continuous increase of the lower and upper margins, or more than one electrographic seizure over a $10 \mathrm{~min}$ period).

\section{Statistical Analysis}

- Data were entered in excel sheet, and then transferred to SPSS version 15 for data analysis.

- The description of the data was done in form of mean (+/-) SD for quantitative data and frequency \& proportion for qualitative data.

- The confidence interval was set to $95 \%$ and the margin of error accepted was set to $5 \%$. So, the p-value was considered as the following: $\mathrm{P}>0.05$ : Non-significant, $\mathrm{P}<0.05$ : Significant, $\mathrm{P}<0.01$ : Highly significant.

\section{Results}

We had 60 preterm infants enrolled in the study, $40 \%$ were females and $60 \%$ were males, their mean gestational age was $32.9 \pm 2.1$, with postnatal age ranged from $4.4 \pm 1.1$, most of the infants were delivered by cesarean section $55 \%$. As regard birth weight, $85 \%$ were appropriate for GA with mean $2.6 \pm 0.23$ while $15 \%$ were small for gestational age (SGA) with mean $2.2 \pm 0.35$. Among our studies group, $26 \%$ had no maternal risk factors while $10 \%$ has PROM $>18 \mathrm{~h}, 10 \%$ had pre-eclampsia, $5 \%$ experienced prolonged difficult deliver and $31.6 \%$ had other as DM, UTI, placenta previa, ...50\% of our patients had convulsions (Table 1).

aEEG results in our patients revealed that $55 \%$ had continuous pattern, $45 \%$ had discontinuous pattern, $30 \%$ had burst suppression and $25 \%$ had spikes. The amplitude was normal in $80 \%$ while it was low in $20 \%$. aEEG detected silent convulsions in $55 \%$ of the patients. As regard the results of cranial US, our study revealed that $5 \%$ had IVH grade I, $5 \%$ had IVH grade II, $10 \%$ had IVH grade III while $80 \%$ were normal (Table 2). 
Table 1. Clinical data of the studied group.

\begin{tabular}{llc}
\hline & & No $=60$ \\
Sex & Female & $24(40 \%)$ \\
Gestational Age (weeks) & Range & $36(60 \%)$ \\
& Mean \pm SD & $26-36 \mathrm{w}$ \\
& Appropriate for GA & $32.9 \pm 2.1$ \\
Birth Weight (kilograms) & Mean \pm SD & $51(85 \%)$ \\
& Small for GA & $2.6 \pm 0.23$ \\
Post-natal age (days) & Mean \pm SD & $9(15 \%)$ \\
Mode of Delivery & Range & $2.2 \pm 0.35$ \\
& Mean \pm SD & $3-7 \mathrm{~d}$ \\
& Vaginal & $4.4 \pm 1.1$ \\
& Cesarean Section & $27(45 \%)$ \\
Apparent Convulsions & No Risk Factors & $33(55 \%)$ \\
& PROM $>$ 18 h & $26(33.3 \%)$ \\
& Pre-eclampsia & $6(10 \%)$ \\
Maternal Risk Factors & Prolonged Difficult Delivery & $6(10 \%)$ \\
& Others (DM, UTI,...) & $3(5 \%)$ \\
& Present & $19(31.6 \%)$ \\
& & $30(50 \%)$ \\
& & $30(50 \%)$ \\
\hline
\end{tabular}

Table 2. The results of aEEG and cranial US of the studied group.

\begin{tabular}{|c|c|c|c|}
\hline & & \multicolumn{2}{|c|}{$\begin{array}{l}\text { Studied patients } \\
\qquad(\mathrm{N}=60)\end{array}$} \\
\hline \multirow{2}{*}{ Continuous } & No & 27 & $45 \%$ \\
\hline & Yes & 33 & $55 \%$ \\
\hline \multirow{2}{*}{ Discontinuous } & No & 33 & $55 \%$ \\
\hline & Yes & 27 & $45 \%$ \\
\hline \multirow{2}{*}{ Burst Suppression } & No & 42 & $70 \%$ \\
\hline & Yes & 18 & $30 \%$ \\
\hline \multirow{2}{*}{ Spikes } & No & 45 & $75 \%$ \\
\hline & Yes & 15 & $25 \%$ \\
\hline \multirow{2}{*}{ Amplitude } & Normal & 48 & $80 \%$ \\
\hline & Low & 12 & $20 \%$ \\
\hline \multirow{2}{*}{ Silent convulsions } & Present & 33 & $55 \%$ \\
\hline & Absent & 27 & $45 \%$ \\
\hline \multirow{2}{*}{ Cranial US } & Normal & 48 & $80 \%$ \\
\hline & IVH & 12 & $20 \%$ \\
\hline \multirow{3}{*}{ IVH grades by Cranial US } & Grade 1 & 3 & $5 \%$ \\
\hline & Grade 2 & 3 & $5 \%$ \\
\hline & Grade 3 & 6 & $10 \%$ \\
\hline
\end{tabular}


As regard the pattern of EEG amplitude and gestational age, our study revealed that the pattern was discontinuous in low gestational age while it became continuous with increase maturation. As regard the birth weight, the pattern was discontinuous in patients small for gestational age while was continuous in patients their weigh is appropriate for GA. As regard convulsions, aEEG shows discontinuous pattern in most of the patients with convulsions. As regard pattern and IVH grades the pattern was continuous in patients with grade I and II while it was discontinuous in patients with grade III (Table 3 ).

There was a high correlation between EEG amplitude and IVH grades. Our study resulted that that amplitude was low in patients with IVH grade III (Table 4).

There was a high correlation between EEG amplitude and complications during delivery, our study resulted that the amplitude of EEG was low in patients whose mothers had pre-eclampsia, PROM and in those who experienced prolonged difficult delivery (Table 5).

Table 3. Shows the relation between pattern of EEG and gestational age, birth weight, convulsions and intraventricular hemorrhage of the studied group.

\begin{tabular}{|c|c|c|c|c|c|c|c|}
\hline & & \multicolumn{6}{|c|}{ Pattern } \\
\hline & & $\begin{array}{l}\text { Continuous } \\
\qquad(\mathrm{N}=33)\end{array}$ & $\begin{array}{l}\text { Discontinuous } \\
\qquad(\mathrm{N}=27)\end{array}$ & $\begin{array}{c}\text { Burst } \\
\text { suppression } \\
(\mathrm{N}=18)\end{array}$ & $\begin{array}{l}\text { Spikes } \\
(\mathrm{N}=15)\end{array}$ & $\mathrm{X}^{2}$ & $\mathrm{p}$-value \\
\hline \multirow{2}{*}{ Gestational Age } & Mean & 34.8 & 31.4 & 32.7 & 31.5 & \multirow{2}{*}{8.09} & \multirow{2}{*}{$<0.001 \mathrm{HS}$} \\
\hline & $\pm \mathrm{SD}$ & 1.13 & 2.04 & 1.58 & 1.03 & & \\
\hline \multirow{4}{*}{ Birth weight } & Appropriate & 33 & 18 & 15 & 15 & \multirow{4}{*}{17.3} & \multirow{4}{*}{$<0.001 \mathrm{HS}$} \\
\hline & for GA & $100 \%$ & $66.7 \%$ & $83.3 \%$ & $100 \%$ & & \\
\hline & \multirow{2}{*}{ Small for GA } & 0 & 9 & 3 & 0 & & \\
\hline & & $0 \%$ & $33.3 \%$ & $16.7 \%$ & $0 \%$ & & \\
\hline \multirow{4}{*}{ Convulsions } & \multirow{2}{*}{ Present } & 9 & 24 & 18 & 15 & \multirow{4}{*}{48.2} & \multirow{4}{*}{$<0.001 \mathrm{HS}$} \\
\hline & & $27.3 \%$ & $88.9 \%$ & $100 \%$ & $100 \%$ & & \\
\hline & \multirow{2}{*}{ Absent } & 24 & 3 & 0 & 0 & & \\
\hline & & $72.7 \%$ & $11.1 \%$ & $0 \%$ & $0 \%$ & & \\
\hline \multirow{6}{*}{ IVH } & \multirow{2}{*}{ Grade I } & 3 & 0 & 0 & 1 & \multirow{6}{*}{13.3} & \multirow{6}{*}{$0.03 \mathrm{~S}$} \\
\hline & & $9 \%$ & $0 \%$ & $0 \%$ & $6.6 \%$ & & \\
\hline & Grode II & 3 & 0 & 1 & 1 & & \\
\hline & Grade il & $9 \%$ & $0 \%$ & $5.5 \%$ & $6.6 \%$ & & \\
\hline & \multirow{2}{*}{ Grade III } & 0 & 6 & 1 & 1 & & \\
\hline & & $0 \%$ & $22.2 \%$ & $5.5 \%$ & $6.6 \%$ & & \\
\hline
\end{tabular}

Table 4. Shows the relation between EEG amplitude and interventricular hemorrhage of the studied group.

\begin{tabular}{|c|c|c|c|c|c|c|}
\hline & & \multicolumn{3}{|c|}{ Amplitude } & \multirow{2}{*}{$\mathrm{X}^{2}$} & \multirow{2}{*}{ P-value } \\
\hline & & Normal $(\mathrm{N}=48)$ & & & & \\
\hline \multirow{3}{*}{ IVH grades } & Grade I & $36.25 \%$ & 0 & $0 \%$ & \multirow{3}{*}{12} & \multirow{3}{*}{$\begin{array}{c}<0.001 \\
\text { HS }\end{array}$} \\
\hline & Grade II & $\begin{array}{c}3 \\
6.25 \%\end{array}$ & 0 & $0 \%$ & & \\
\hline & Grade III & $\begin{array}{c}0 \\
0 \%\end{array}$ & 6 & $50 \%$ & & \\
\hline
\end{tabular}


Table 5. Shows the relation between EEG amplitude and complications during delivery of the studied group.

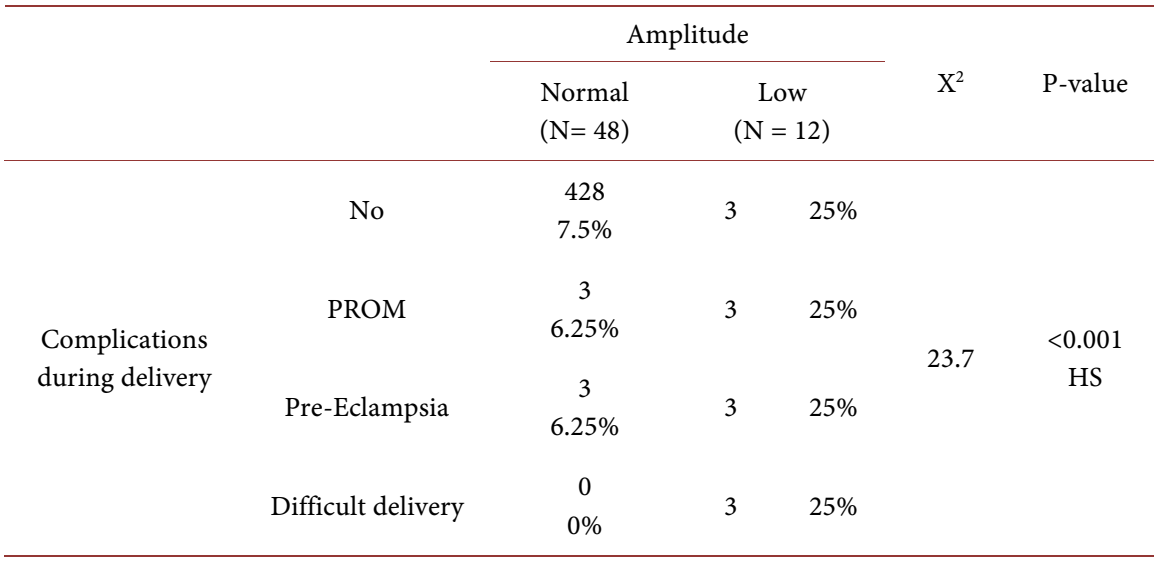

\section{Discussion}

Our study aEEG of the included neonates was burst suppression pattern in 18 patients (30\%) and spikes pattern in 15 patients (25\%) had spikes, that may be an indicator of long term complications as epilepsy. $20 \%$ had low voltage background indicator of neurodevelopmental complications later on.

High statistically significant relation ( $\mathrm{p}$-value $<0.001$ ) was between EEG pattern and gestational age in all studied patients. Gestational age was lower in patients with discontinuous pattern. aEEG appears to represent an increase in continuity of the EEG, as continuity increases with maturation. This can be explained by rapid increase in cerebral cortical volume [4]. In the very preterm infant, the EEG background activity is characterized by discontinuity, instability, and fragmentation. The greater the prematurity, the more marked are these at aEEG aspects [5].

High statistically significant relation (p-value $<0.001$ ) was between aEEG pattern and birth weight in all studied patients. There were 9 patients (33.3\%) SGA with discontinuous pattern. Griesmaier et al. [6] reported similar finding. The preterm infants whose SGA had discontinuous pattern and burst suppression more in comparison to those appropriate for GA.

Several studies have evaluated the sensitivity and specificity of aEEG for the diagnosis of neonatal seizures with variable results. However, these studies have not addressed the importance of electrophysiological interpretation of aEEG findings [7]. Our study revealed that 33 patients (55\%) of the included preterm infants had silent convulsions while only 30 patients had apparent convulsions and 18 patients with burst suppression. Highly statistically significant relation (p-value $<0.001$ ) between aEEG pattern and silent convulsions was in all studied patients. The brain function signal develops to reflect a primarily discontinuous EEG pattern early in life with functional maturation to more continuous signal as the infant approaches term gestation [8]. Sousa et al. [9] revealed that electrographic seizures observed in the first week of life could be related to adverse outcomes that could affect the neonate in the future. 
Intraventricular hemorrhage (IVH) and its complications are the main cause of neonatal seizures in very and extremely preterm newborns ( $<32$ weeks) [10], and the risk increases with increasing severity of brain injury (grades III and IV IVH). On the other hand, in moderate and late preterm infants the majority of seizures are caused by HIE which shows $40 \%$ - $60 \%$ in near-term newborns with seizures [11]. In our studied group, there were 12 patients (10\%) with IVH diagnosed by cranial US, 3 patients with IVH grad I, 3 patients with IVH grade II and 6 patients with IVH grade III. Our study resulted in a high statistical significant relation ( $p$-value $<0.001$ ) between EEG amplitude and IVH grades and nearly statistically significant relation ( $p$-value $<0.05$ ) between aEEG pattern and IVH grades in all studies patients. The 6 patients with IVH grade III had low amplitude, low voltage burst suppression and discontinuous pattern while the 6 patients with grade IVH I and II had normal amplitude with continuous pattern. Our study agrees with Chalak et al. [12], who recorded aEEG in patients with severe IVH and resulted that most of the patients had low voltage amplitude with burst suppression and discontinuous pattern. IVH and its subsequent effects, specifically, influence a number of aEEG characteristics. When compared with age matched controls, premature infants $<30$ weeks of GA with IVH show increased discontinuity and seizures. This effect was more pronounced in patients with more significant bleeding [13]. Our study also agrees with Tao et al. [14].

Our study revealed that 15 patients had complications during delivery, 6 patients (10\%) with mothers had PROM more than 18 hours before delivery, 6 patients (10\%) with pre-eclampsia and 3 patients (5\%) had prolonged delivery.

As regard aEEG in patients whose mothers had pre-eclampsia, 3 of them had low voltage amplitude and the other 3 had normal amplitude. Preeclampsia leads to chronic intrauterine hypoxia by interfering with placental blood supply and as a sequel alters cerebral electrical activity of premature infants. Topcuoglu et al. [15] reported a similar finding.

As regard aEEG in patients whose mothers had PROM, 3 of them had normal amplitude EEG while the other 3 had low voltage amplitude. Paz-Levy et al. [16] reported a similar finding. Placental lesions consistent with amniotic fluid infection of the fetal side of the placenta were associated with absence or depressed cycling of aEEG. Previous reports found an association between the absence of neonatal aEEG cycling and abnormal neurodevelopmental outcome [17].

As regard aEEG in patients with difficult prolonged delivery, they had low voltage amplitude. The prolonged delivery can lead to neonatal asphyxia which leads to brain injury and ischemia and as a sequel altered brain activity. Our study agrees with Variane et al. [18], where he studied 23 patients with perinatal asphyxia resulted in discontinuous low voltage pattern aEEG.

The brain damage caused by many risk factors such as PROM, preeclampsia and perinatal asphyxia often causes the death of premature infants and subsequent neurological development disorders such as cerebral palsy, epilepsy, men- 
tal retardation, and visual and auditory impairments [19]. Impaired cerebral activity, as reflected by depressed activity or absence of cycling in aEEG recorded during the first 3 days of life, was reported by different researchers using different methodologies, to be predictive of white matter injury, short and long term adverse outcomes [20].

\section{Conclusion}

Neurological complications related to prematurity are not uncommon among preterm neonates, and cranial U/S was normal in most of the included neonates (80\%) who were suspected to have neurological problems. Discontinuous pattern is the commonest EEG pattern in premature neonates. aEEG is a useful method for detection of silent convulsions, as seizures noted by aEEG may provide an alert for the physician that neonate is undergoing a significant acute event such as IVH, HIE and monitoring neonatal brain functions. aEEG background activity changes may be strongly correlated with gestational age and birth weight. aEEG has high sensitivity, specificity, and prognostic value for the monitoring of early-born infants with severe brain injury.

\section{Recommendations}

1) Training in the aEEG tracing and interfere with its interpretation and consequently the prognostic evaluation is needed.

2) Training in the aEEG assessment and knowledge of the potential aEEG signal confounders is needed in order to better further promising neuro-monitoring tool in NICU.

Long term follows up for neonates with aEEG abnormalities for early identification and treatment of neurodevelopmental abnormalities.

\section{Conflicts of Interest}

The authors declare no conflicts of interest regarding the publication of this paper.

\section{References}

[1] Lien, R. (2020) Neurocritical Care of Premature Infants. Biomedical Journal, 43, 259-267. https://doi.org/10.1016/j.bj.2020.03.007

[2] Meledin, I., Tzur-Sebton, H., Noyman, I., Friger, M., Hazan, G. and Shany, E. (2019) Seizures in Premature Infants Born at Less than 28 Weeks' Gestation. Neonatology, 115, 247-255. https://doi.org/10.1159/000494626

[3] Haartsen, R., van der Velde, B., Jones, E.J., Johnson, M.H. and Kemner, C. (2020) Using Multiple Short Epochs Optimises the Stability of Infant EEG Connectivity Parameters. Scientific Reports, 10, Article No. 12703. https://doi.org/10.1038/s41598-020-68981-5

[4] Kapellou, O., Counsell, S.J., Kennea, N., Dyet, L., Saeed, N., Stark, J., et al. (2006) Abnormal Cortical Development after Premature Birth Shown by Altered Allometric Scaling of Brain Growth. PLOS Medicine, 3, e265. 
https://doi.org/10.1371/journal.pmed.0030265

[5] Niemarkt, H., Jennekens, W., Pasman, J., et al. (2011) Maturational Changes in Automated EEG Spectral Power Analysis in Preterm Infants. Pediatric Research, 70, 529-534. https://doi.org/10.1203/PDR.0b013e31822d748b

[6] Griesmaier, E., Burger, C., Ralser, E., Neubauer, V. and Kiechl-Kohlendorfer, U. (2015) Amplitude-Integrated Electroencephalography Shows Mild Delays in Electrocortical Activity in Preterm Infants Born Small for Gestational Age. Acta Paediatrica, 104, e283-e288. https://doi.org/10.1111/apa.12967

[7] Rakshasbhuvankar, A., Rao, S., Palumbo, L., Ghosh, S. and Nagarajan, L. (2017) Amplitude Integrated Electroencephalography Compared with Conventional Video EEG for Neonatal Seizure Detection: A Diagnostic Accuracy Study. Journal of Child Neurology, 32, 815-822. https://doi.org/10.1177/0883073817707411

[8] Thorngate, L., Foreman, S. and Thomas, K. (2013) Quantification of Neonatal Amplitude-Integrated EEG Patterns. Early Human Development Journal, 89, 931-937. https://doi.org/10.1016/j.earlhumdev.2013.09.018

[9] Sousa, T.M.A.D., Gugelmin, V.S., Fernandes, G.M., Aucélio, C.N., Costa, K.N. and Tristão, R.M. (2019) Comparison of Conventional, Amplitude-Integrated and Geodesic Sensor Net EEG Used in Premature Neonates: A Systematic Review. Arquivos de neuro-psiquiatria, 77, 260-267. https://doi.org/10.1590/0004-282x20190030

[10] Pisani, F., Facini, C., Pelosi, A., Mazzotta, S., Spagnoli, C. and Pavlidis, E. (2016) Neonatal Seizures in Preterm Newborns: A Predictive Model for Outcome. European Journal of Paediatric Neurology, 20, 243-251.

https://doi.org/10.1016/j.ejpn.2015.12.007

[11] Glass, H.C., Shellhaas, R.A., Tsuchida, T.N., Chang, T., Wusthoff, C.J., Chu, C.J., et al. (2017) Seizures in Preterm Neonates: A Multicenter Observational Cohort Study. Journal of Pediatric Neurology, 72, 19-24. https://doi.org/10.1016/j.pediatrneurol.2017.04.016

[12] Chalak, L.F., Sikes, N.C., Mason, M.J. and Kaiser, J.R. (2011) Low-Voltage a EEG as Predictor of Intracranial Hemorrhage in Preterm Infants. Journal of Paediatric Neurology, 44, 364-369. https://doi.org/10.1016/j.pediatrneurol.2010.11.018

[13] Olischar, M., Klebermass, K., Hengl, B., Hunt, R.W., Waldhoer, T., Pollak, A. and Weninger, M. (2009) Cerebrospinal Fluid Drainage in Posthemorrhagic Ventricular Dilatation Leads to Improvement in Amplitude-Integrated Electroencephalographic Activity. Acta Paediatrica, 98, 1002-1009. https://doi.org/10.1111/j.1651-2227.2009.01252.x

[14] Tao, J.D. and Mathur, A.M. (2010) Using Amplitude-Integrated EEG in Neonatal Intensive Care. Journal of Perinatology, 30, S73-S81.

https://doi.org/10.1038/jp.2010.93

[15] Topcuoglu, S., Kolsuz, L.D., Gursoy, T., Ovali, F. and Karatekin, G. (2016) Effects of Preeclampsia on the Amplitude Integrated Electroencephalography Activity in Preterm Infants. Journal of Perinatal Medicine, 44, 345-349.

https://doi.org/10.1515/jpm-2015-0096

[16] Paz-Levy, D., Schreiber, L., Erez, O., Goshen, S., Richardson, J., Drunov, V., Chacham, O.S. and Shany, E. (2017) Inflammatory and Vascular Placental Lesions Are Associated with Neonatal Amplitude Integrated EEG Recording in Early Premature Neonates. PLoS ONE, 12, e0179481.

https://doi.org/10.1371/journal.pone.0179481

[17] Song, J., Xu, F., Wang, L., et al. (2015) Early Amplitude-Integrated Electroencephalography Predicts Brain Injury and Neurological Outcome in Very Preterm Infants. 
Scientific Reports, 5, Article No. 13810. https://doi.org/10.1038/srep13810

[18] Variane, G.F., Magalhães, M., Gasperine, R., Alves, H.C., Scoppetta, T.L., Figueredo, R.J., et al. (2016) Early Amplitude-Integrated Electroencephalography for Monitoring Neonates at High Risk for Brain Injury. Jornal de Pediatria, 93, 460-466. https://doi.org/10.1016/j.jped.2016.12.003

[19] Guo, X., Geng, Y., Zhang, L., Niu, S. and Xuecorresponding, J. (2021) Early Diagnosis of Brain Injury in Premature Infants Based on Amplitude-Integrated EEG Scoring System. Journal of Healthcare Engineering, 2021, Article ID: 6684818. https://doi.org/10.1155/2021/6684818

[20] Wikström, S., Pupp, I.H., Rosén, I., Norman, E., Fellman, V., Ley, D. and Hellström-Westas, L. (2012) Early Single-Channel a EEG/EEG Predicts Outcome in Very Preterm Infants. Acta Paediatrica, 101, 719-726.

https://doi.org/10.1111/j.1651-2227.2012.02677.x 